\title{
A New Dynamic Prediction Model for Underground Mining Subsidence Based on Inverse Function of Unstable Creep
}

\author{
Hua Cheng, ${ }^{1,2}$ Liangliang Zhang $\mathbb{D}^{1}{ }^{1}$ Longhui Guo, ${ }^{1}$ Xiaojian Wang, ${ }^{1}$ and Shilong Peng ${ }^{3}$ \\ ${ }^{1}$ School of Civil Engineering and Architecture, Anhui University of Science and Technology, Huainan 232001, China \\ ${ }^{2}$ School of Resources and Environmental Engineering, Anhui University, Hefei 230022, China \\ ${ }^{3}$ School of Civil Engineering, Anhui Jianzhu University, Hefei, 230601, China \\ Correspondence should be addressed to Liangliang Zhang; zllaust@163.com
}

Received 6 April 2021; Accepted 20 May 2021; Published 28 May 2021

Academic Editor: Hao Wu

Copyright (c) 2021 Hua Cheng et al. This is an open access article distributed under the Creative Commons Attribution License, which permits unrestricted use, distribution, and reproduction in any medium, provided the original work is properly cited.

In this study, an improved Knothe time function model is established via analogical reasoning from a phenomenological perspective, based on an inverse "Hohai creep model" function, in accordance with the antisymmetric relationship between the unstable creep curve and surface dynamic subsidence curve. An empirical method and fitting method are proposed to determine the parameters of the improved model based on the availability of measured field data. The accuracies of the two models are compared with monitored data from eight monitoring points in the main strike profile of the Guotun coal mine subsidence basin. The results show that the improved model can more accurately reflect the dynamic process of surface subsidence. The average relative standard deviation of the improved model is only $4.9 \%$, which is far lower than the $23.1 \%$ associated with the Knothe model. This verifies the improved model's accuracy and reliability. The model parameters for different monitoring stations obtained using the fitting method are similar, which shows that the model parameters are regular and can be easily applied.

\section{Introduction}

The surface subsidence caused by coal mining is a dynamic process $[1,2]$. A series of problems associated with surface subsidence, including environmental deterioration, land desertification, groundwater level decline, and the formation of ground-based building and infrastructure cracks, have been a concern within academic and engineering field [3]. The accurate prediction and effective control of surface subsidence in order to recommend reasonable excavation schemes and ground building protection measures has thus been identified as a difficult problem requiring solution [4]. Surface subsidence is not only related to the hydrogeological conditions of coal seams but is also closely related to mining methods and processes. With the increase of the scope of goaf, the mining-related range of surface-level disturbance expands, and a stable subsidence basin gradually forms on the surface after mining is halted for a period of time. The scale of the subsidence basin is far larger than that of the mined-out area. A specific point on the surface will experience the whole process of initial subsidence, rapid subsidence, and slow subsidence before finally reaching a stable state $[5,6]$. Therefore, surface subsidence is a continuous function of time, and the key to accurate prediction of surface subsidence is the determination of the time function model and the model parameters.

At present, Knothe time function model is widely used in mining engineering. However, with more in-depth research, the shortcomings of the Knothe time function model are becoming increasingly apparent $[7,8]$. Therefore, many experts use the methods of parameter modification, piecewise modeling, and theoretical analysis to establish more accurate and applicable prediction models. Hu et al. $[9,10]$ proposed the probability integral method to solve the parameters of the Knothe time function model according to the general characteristics of surface movement and deformation caused by mining subsidence and the critical size of the goaf when fully mined out. Cui et al. [11] proposed Knothe time function model parameters in line with real-world situations by comprehensively considering the driving speed 
of the working face and the critical size of the goaf during full mining. Liu and Zhuang $[12,13]$ added a power index with constant $K$ as a parameter in the Knothe time function and put forward an improved Knothe model in line with the actual surface subsidence characteristics. Li [14] proposed the concept of overburden lithologic parameters and established the relationship between these parameters and the time function model parameters, thus improving the Knothe time function model. Taherynia et al. [15] used a circular network to determine the compaction effect of the entire reservoir on the field surface, based on the Knothe and Geertsma influence functions.

These research results have been well applied to the prediction of surface subsidence in coal mining. However, there are many defects in the model, such as the large number of parameters and the difficulty involved in their determination. In this study, an inverse "Hohai creep model" function is solved according to the antisymmetric relationship between the unstable creep curve and the surface dynamic subsidence curve. From a phenomenological perspective, an improved Knothe time function model based on an inverse "Hohai creep model" function is established by analogical reasoning. Additionally, the rationality and applicability of the improved model are verified by using monitored data from the main profile of the surface strike of the 1301 working face in the Guotun mine.

\section{Knothe Time Function Model}

The Knothe time function model was proposed by the Polish scholar Knothe in 1952 [16]. At present, it is widely used to predict the dynamic subsidence of a specific point on the surface caused by mining. The expression of Knothe time function model is as follows $[17,18]$ :

$$
\left\{\begin{array}{l}
W(t)=W_{0}\left(1-e^{-c t}\right), \\
V(t)=c W_{0} e^{-c t}, \\
a(t)=-c^{2} W_{0} e^{-c t},
\end{array}\right.
$$

where $c$ is a time influence parameter; $W(t)$ is the surface subsidence; $V(t)$ is the subsidence velocity; $a(t)$ is the surface subsidence acceleration.

According to equation (1), the Knothe time function curve is obtained, as shown in Figure 1.

According to equation (1) and Figure 1, it can be seen that the surface subsidence increases gradually, $V(t)$ decreases gradually, and $a(t)$ is always less than 0 throughout the subsidence process, which is clearly inconsistent with the actual surface subsidence characteristics.

Lots of field monitoring data show that the process of surface subsidence can generally be divided into initial subsidence, rapid subsidence, and slow subsidence to a stable state. The surface subsidence curve approximates an "S" type curve, while the surface subsidence velocity curve approximates a normal distribution curve $[19,20]$. However, $W(t)$, $V(t)$, and $a(t)$ represented by Knothe model are monotonic functions of time, so the model is not suitable for describing the dynamic surface subsidence process.

\section{Improved Knothe Model}

According to the rock creep theory, rock will undergo unstable creep under high stress levels as shown in the blue curve in Figure 2 (the curve does not include the instantaneous strain generated during stress loading). It can be seen that the shape of the unstable creep curve is similar to a reverse "S" curve, which is the inverse of the surface subsidence curve. In view of this and taking $\varepsilon(t)=t$ as the axis of symmetry, it is proposed that the inverse image of the unstable creep curve can be obtained as shown by the red " $S$ " curve in Figure 2, and this can be used to describe dynamic surface subsidence. According to basic mathematics, the functions represented by the red curve and the blue curve are inverse functions of each other. Therefore, as long as the unstable creep function is determined and its inverse function is calculated, the time function describing the dynamic surface subsidence can be established.

The establishment of the unstable creep function is always a difficulty in the study of rock creep mechanics. Because the parameters of the classical Kelvin creep model, the Burgers creep model, and the Nishihara creep model do not change with time, it is difficult to use these models to describe the unstable creep that occurs when the stress exceeds the long-term strength of rock [21]. In order to effectively solve this problem, experts have proposed the use of nonlinear elements as replacements for the linear elements present in the classical models to establish a nonlinear creep model that can describe unstable rock creep. This has led to the establishment of the "Hohai creep model" [22]. In this model, the ideal viscous body is replaced by a nonlinear viscous body and paralleled with a plastic body. The "Hohai creep model" can be used to describe unstable rock creep. The "Hohai creep" mechanical model is shown in Figure 3.

According to the nonlinear creep theory, the differential constitutive relation of the "Hohai creep model" can be obtained as follows:

$$
\sigma-\sigma_{S}=\frac{\eta}{n t^{n-1}} \frac{\mathrm{d} \varepsilon(t)}{\mathrm{d} t},
$$

where $\sigma$ is stress; $\sigma_{S}$ is long-term strength; $\eta$ is the viscosity coefficient of the "Hohai creep model"; $n$ is model order; $\varepsilon$ is strain; and $t$ is time.

$(\mathrm{d} \varepsilon(t) / \mathrm{d} t)$ in equation (2) is regarded as the independent variable $x$ and $\sigma-\sigma_{S}$ as the dependent variable $y$. The functional relationship between $x$ and $y$ can then be obtained as follows:

$$
y=\frac{\eta}{n t^{(n-1)}} x
$$

The inverse function of equation (3) can be solved to obtain the new relationship between the independent and dependent variables. At this time, the independent variable 

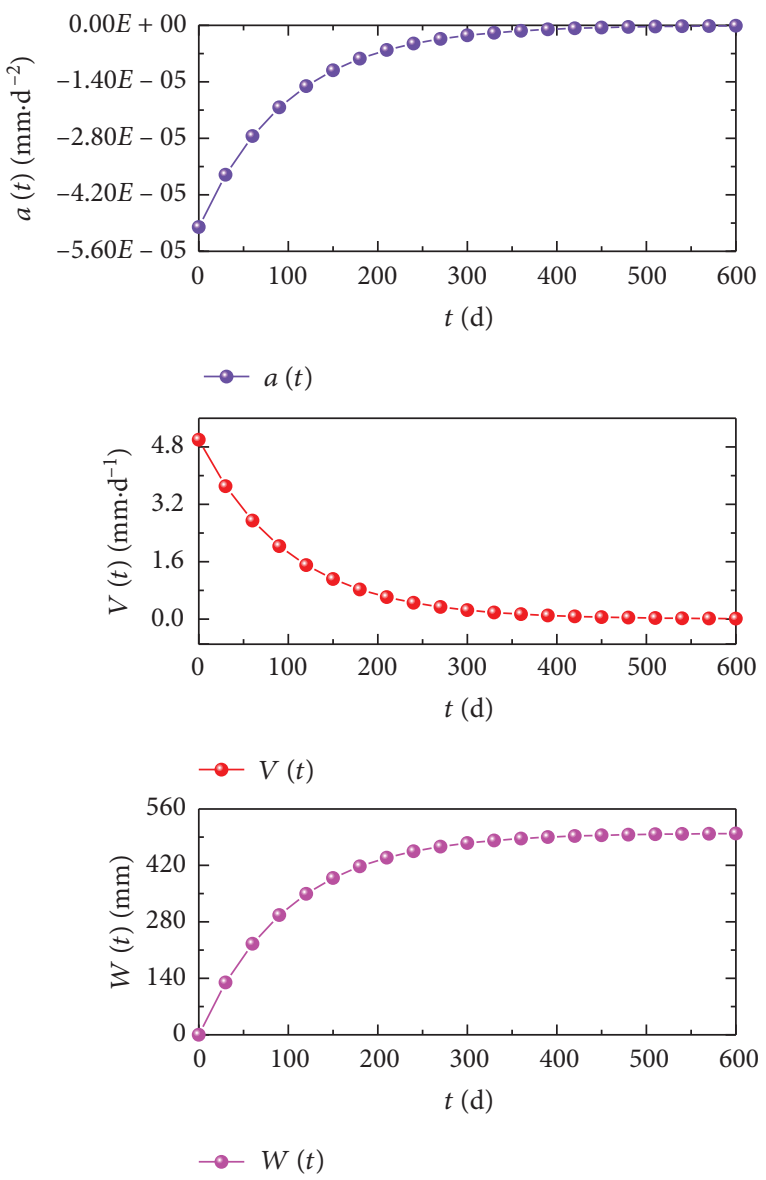

Figure 1: The Knothe time function curve.

is $\sigma-\sigma_{S}$ and the dependent variable is $(\mathrm{d} \varepsilon(t) / \mathrm{d} t)$. Therefore, the inverse function of equation (3) can be expressed as follows:

$$
\frac{\mathrm{d} \varepsilon(t)}{\mathrm{d} t}=\frac{n t^{n-1}}{\eta}\left(\sigma-\sigma_{S}\right)
$$

From the perspective of phenomenology, we can use analogical reasoning to equate $(\mathrm{d} \varepsilon(t) / \mathrm{d} t)$ to $(\mathrm{d} W(t) / \mathrm{d} t)$, $(1 / \eta)$ to $C, \sigma$ to $W_{0}$, and $\sigma_{S}$ to $W(t)$. This allows the proposal of an improved Knothe model expression as follows:

$$
\frac{\mathrm{d} W(t)}{\mathrm{d} t}=C n t^{n-1}\left[W_{0}-W(t)\right]
$$

where $C$ is a time influence parameter of the improved model.

Solving equation (5) and considering the initial condition $\left.W(t)\right|_{t=0}=0$, equation (5) can then be simplified as follows:

$$
W(t)=W_{0}\left[1-\exp \left(-C t^{n}\right)\right]
$$

The dynamic surface subsidence velocity and acceleration can then be derived from equation (6) as follows:

$$
\left\{\begin{array}{l}
V(t)=W_{0} C n t^{n-1} \exp \left(-C t^{n}\right) \\
a(t)=W_{0} C n \exp \left(-C t^{n}\right)\left[(n-1) t^{n-2}-C n t^{2 n-2}\right] .
\end{array}\right.
$$

When $n=1$, equations $(6) \sim(7)$ can be simplified into equation (1), which shows that the Knothe model is a special case of the improved model established in this study.

The surface subsidence curve, subsidence velocity curve, and subsidence acceleration curve of the improved model are shown in Figure 4. It can be seen that the surface subsidence curve is approximately S-shaped, and the surface subsidence velocity curve approximates a normal distribution curve. The surface subsidence characteristics that are reflected are consistent with the real-world process and can thus be used to describe the dynamic process of surface subsidence.

\section{Determination of Model Parameters}

According to equation (6), there are only two parameters in the improved model: $C$ and $n$. Therefore, compared with the Knothe model, the improved model is not only more 


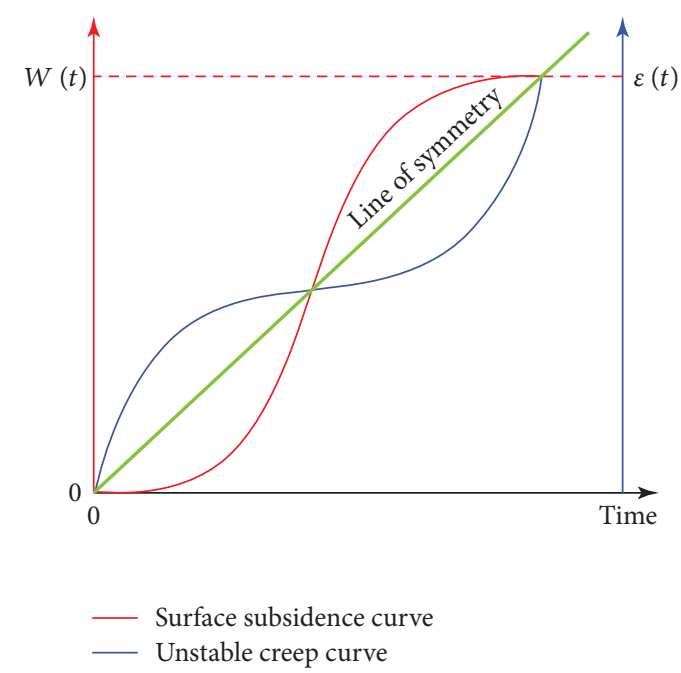

FIGURE 2: Unstable creep and surface subsidence curves.

accurate but is also easily applied in the field due to the reduced number of required parameters. Additionally, its practical operability is superior to other complex improved models.

4.1. Empirical Method. By analyzing a large amount of surface subsidence monitoring data, we can get the following empirical equation [23]:

$$
\left.W(t)\right|_{V(t)=V_{\max }}=0.98 W_{0} .
$$

Taking equation (9) into equation (7), we get $n=3.26$.

According to empirical analysis and research, when the length of goaf reaches the full mining value, $W_{\max }$ will be approximately $0.98 W_{0}$ [24]. According to equation (6), the parameter $C$ can be calculated as follows:

$$
0.98 W_{0}=W_{0}\left[1-\exp \left(-C\left(\frac{2 H}{v \tan \varphi}\right)^{3.26}\right)\right]
$$

where $(2 H / \tan \varphi)$ is the critical gob dimension [25], $v$ is the mining velocity, $H$ is the seam depth, and $\varphi$ is the full subsidence angle.

Equation (9) is simplified and the parameter $C$ is obtained as follows:

$$
C=-\left(\frac{v \tan \varphi}{2 H}\right)^{3.26} \ln 0.02
$$

4.2. Fitting Method. The empirical method mentioned in Section 4.1 has the following limitations:

(1) When determining the parameters $C$ and $n$, it is necessary to determine the time when the surface subsidence reaches its maximum velocity along with the critical gob dimension $L_{f}$. However, these two parameters are not easy to determine accurately for actual coal seam mining.
(2) Due to the application of different mining methods and differing geological conditions, not all surface point subsidence values are half of the final subsidence value when the subsidence velocity reaches its maximum value. In addition, neither is the maximum surface subsidence equal to $0.98 W_{0}$ when the scale of the coal seam mining reaches the critical value of full mining.

Therefore, $C$ and $n$ determined by applying empirical methods are associated with a certain error that is independent of the error caused by measurement. When there is a large amount of surface subsidence monitored data, the fitting method [26] can be used to determine the improved Knothe time function model parameters according to the field monitoring data. This method can ensure minimization of the error between the fitting value and the monitored value. In addition, it is easy to use and is thus widely favored by researchers.

\section{Model Validation}

Monitored data and results predicted by the model were compared and analyzed in order to verify the rationality of the improved model. The surface subsidence monitored data from the 1301 working face in Guotun coal mine, Shandong Province, China, were used in the investigation. The 1301 working face is located to the southwest of the Juye mining area. The coal seam thickness varies from 1 to $3.6 \mathrm{~m}$, and the dip angle is $12^{\circ}$. Mining began on the working face in the first ten days of November 2010 and ended in the middle of December 2012. The first observation was performed on October 18, 2010, and the maximum detected surface subsidence was $16 \mathrm{~mm}$.

The length of the strike observation line of the 1301 working face is $4200 \mathrm{~m}$. It contains 126 monitoring points, numbered Z1-Z126. The length of the inclination observation line is $2300 \mathrm{~m}$, and it contains 60 monitoring points, numbered $\mathrm{H} 1-\mathrm{H} 60$. The distance between two adjacent monitoring points is $30 \mathrm{~m}$. To satisfy the requirements of this 


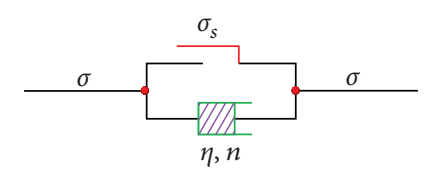

FIGURE 3: "Hohai creep model."

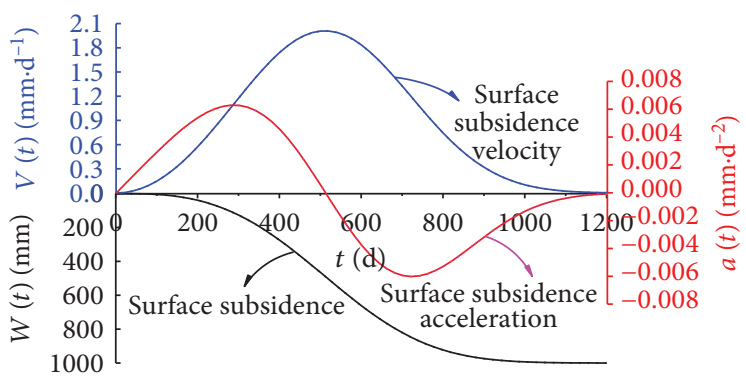

FIgURE 4: Subsidence, subsidence velocity, and subsidence acceleration curve of improved Knothe model.

research, the layout of some monitoring points was selected as shown in Figure 5. Due to the extended observation duration and the large amount of monitored data, monitored data from points Z29, Z37, Z41, Z44, Z45, Z47, Z50, and $\mathrm{Z} 53$ were randomly selected to analyze the accuracy of the Knothe time function model and the improved Knothe time function model in terms of surface subsidence prediction.

Table 1 shows the measured subsidence values from 8 monitoring points taken at different dates. It can be seen from the table that the final stable subsidence values of Z29 and Z37 are smaller than those of the other monitoring points. However, the subsidence trend at all monitoring points shows a clear " $\mathrm{S}$ " shape, allowing the phenomenon to be described by the improved model.

Combined with the monitored data, the Knothe model and the improved model were used to predict the surface subsidence. The results obtained using the two models can be compared with the measured data from the eight monitoring points, as shown in Figure 6.

The parameters of the improved model and Knothe model were determined according to the fitting method as shown in Table 2. It can be seen from a comparison of the results shown in Figure 5 that there is a big difference between the fitted values of the Knothe time function model and the monitored data. Additionally, the model curve flows a gradual slope with respect to time, which does not reflect the "S" type curve of surface point subsidence with respect to time. The improved model curve is highly consistent with the monitored data, which accurately reflects the dynamic characteristics of surface point subsidence with respect to time. In addition, the model parameters $C$ and $n$ obtained by fitting the monitored data of monitoring points Z41, Z44, Z45, Z47, Z50, and Z53 are similar, showing little difference. This indicates that the model is relatively stable and that the model parameters are regular and easily applied.

\section{Discussion}

As shown in equation (11), the standard deviation $m$ and relative standard deviation $f$ can be used to verify the accuracy of the improved model. The calculation results are shown in Table 3. From Table 3, we can see that the improved model's average relative standard deviation was only $4.9 \%$, which is far lower than the $23.1 \%$ of the Knothe model. Although the accuracy of the improved Knothe time function model is higher than that of the Knothe model, the improved model is only suitable for describing the law of surface subsidence after full mining and can not accurately reflect the characteristics of surface subsidence in the process of insufficient mining.

$$
\left\{\begin{array}{l}
m= \pm \sqrt{\frac{\sum_{i=1}^{N}\left(W_{j}-W_{l}\right)^{2}}{N-1}}, \\
f=\left|\frac{m}{W_{0}}\right|
\end{array}\right.
$$




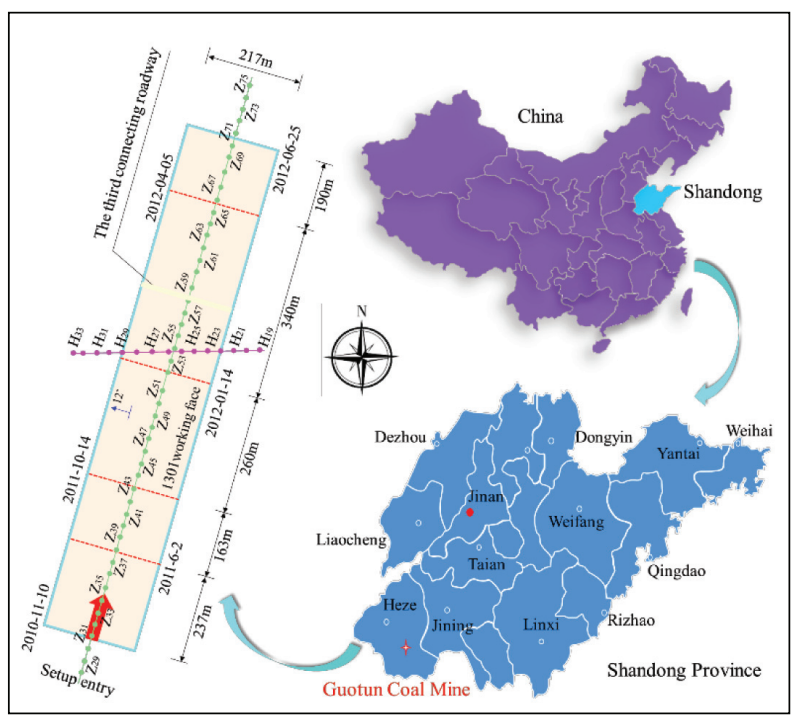

FIgURE 5: The location of 1301 working face.

TABLE 1: Surface subsidence monitored data from Z29, Z3, Z41, Z44, Z45, Z47, Z50, and Z53.

\begin{tabular}{|c|c|c|c|c|c|c|c|c|c|c|}
\hline \multirow{2}{*}{ Observation times } & \multirow{2}{*}{ Observation date } & \multirow{2}{*}{ Relative observation (time/d) } & \multicolumn{8}{|c|}{ Subsidence (value/mm) } \\
\hline & & & Z29 & $\mathrm{Z} 37$ & $\mathrm{Z} 41$ & Z44 & Z45 & $\mathrm{Z} 47$ & $\mathrm{Z} 50$ & Z53 \\
\hline 1 & $2010 / 10 / 18$ & 0 & 0 & 0 & 0 & 0 & 0 & 0 & 0 & 0 \\
\hline 2 & $2010 / 12 / 27$ & 69 & 0.006 & 0.006 & 0.006 & 0.005 & 0.005 & 0.006 & 0.003 & 0.004 \\
\hline 3 & $2011 / 1 / 23$ & 95 & 0.012 & 0.008 & 0.007 & 0.006 & 0.004 & 0.007 & 0.006 & 0.003 \\
\hline 4 & $2011 / 3 / 2$ & 134 & 0.020 & 0.018 & 0.017 & 0.014 & 0.010 & 0.011 & 0.009 & 0.010 \\
\hline 5 & $2011 / 3 / 27$ & 159 & 0.027 & 0.024 & 0.020 & 0.015 & 0.009 & 0.009 & 0.006 & 0.005 \\
\hline 6 & $2011 / 4 / 27$ & 189 & 0.066 & 0.074 & 0.055 & 0.039 & 0.030 & 0.026 & 0.013 & 0.008 \\
\hline 7 & $2011 / 5 / 14$ & 206 & 0.080 & 0.097 & 0.066 & 0.046 & 0.036 & 0.028 & 0.014 & 0.008 \\
\hline 8 & $2011 / 6 / 2$ & 224 & 0.104 & 0.126 & 0.100 & 0.071 & 0.058 & 0.047 & 0.026 & 0.014 \\
\hline 9 & $2011 / 6 / 29$ & 251 & 0.138 & 0.185 & 0.151 & 0.109 & 0.092 & 0.074 & 0.041 & 0.023 \\
\hline 10 & $2011 / 7 / 27$ & 279 & 0.153 & 0.227 & 0.189 & 0.137 & 0.119 & 0.092 & 0.043 & 0.024 \\
\hline 11 & $2011 / 9 / 17$ & 329 & 0.168 & 0.249 & 0.208 & 0.151 & 0.131 & 0.102 & 0.045 & 0.025 \\
\hline 12 & $2011 / 10 / 14$ & 356 & 0.241 & 0.394 & 0.371 & 0.296 & 0.265 & 0.211 & 0.133 & 0.080 \\
\hline 13 & $2011 / 11 / 3$ & 375 & 0.283 & 0.498 & 0.630 & 0.569 & 0.440 & 0.370 & 0.241 & 0.142 \\
\hline 14 & $2012 / 1 / 14$ & 446 & 0.305 & 0.619 & 0.717 & 0.713 & 0.687 & 0.630 & 0.489 & 0.333 \\
\hline 15 & $2012 / 3 / 4$ & 496 & 0.342 & 0.700 & 0.859 & 0.916 & 0.917 & 0.898 & 0.829 & 0.691 \\
\hline 16 & $2012 / 4 / 5$ & 527 & 0.364 & 0.735 & 0.919 & 1.003 & 1.015 & 1.018 & 1.005 & 0.926 \\
\hline 17 & $2012 / 5 / 15$ & 567 & 0.373 & 0.750 & 0.940 & 1.033 & 1.050 & 1.060 & 1.070 & 1.022 \\
\hline 18 & $2012 / 6 / 25$ & 607 & 0.383 & 0.765 & 0.960 & 1.063 & 1.085 & 1.103 & 1.136 & 1.119 \\
\hline 19 & $2012 / 7 / 24$ & 636 & 0.390 & 0.773 & 0.969 & 1.072 & 1.094 & 1.112 & 1.147 & 1.130 \\
\hline
\end{tabular}




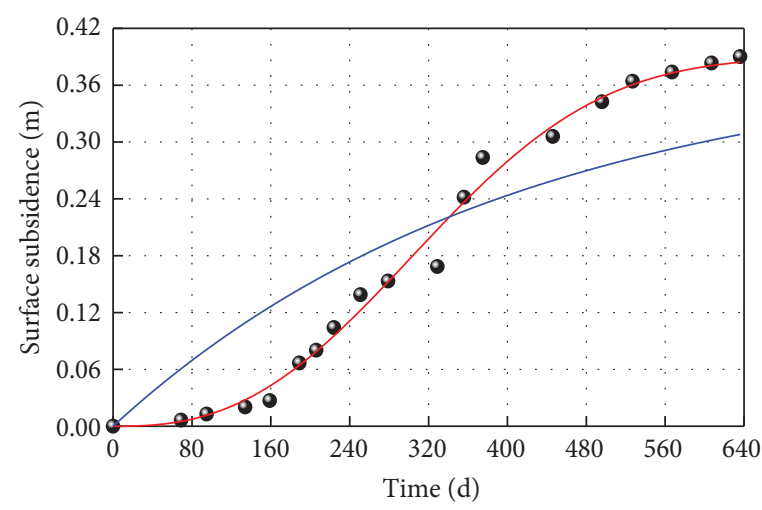

- Z29 monitoring data

- Improved Knothe model curve

_ Knothe model curve

(a)

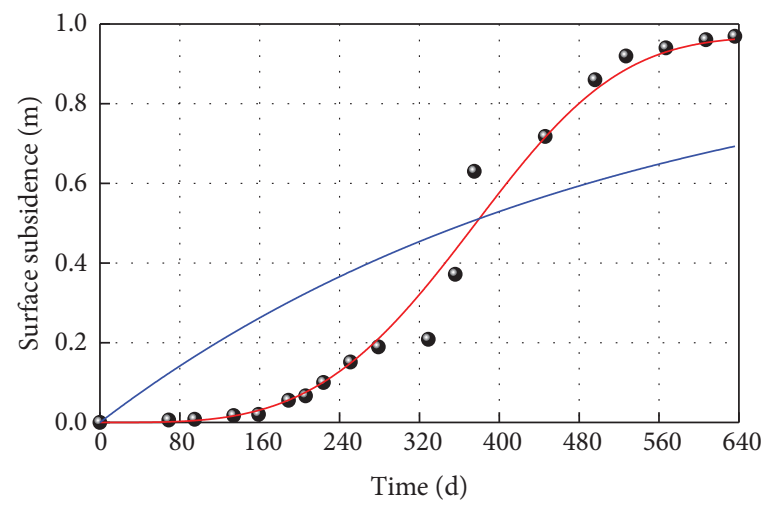

- Z41 monitoring data

Improved Knothe model curve

Knothe model curve

(c)

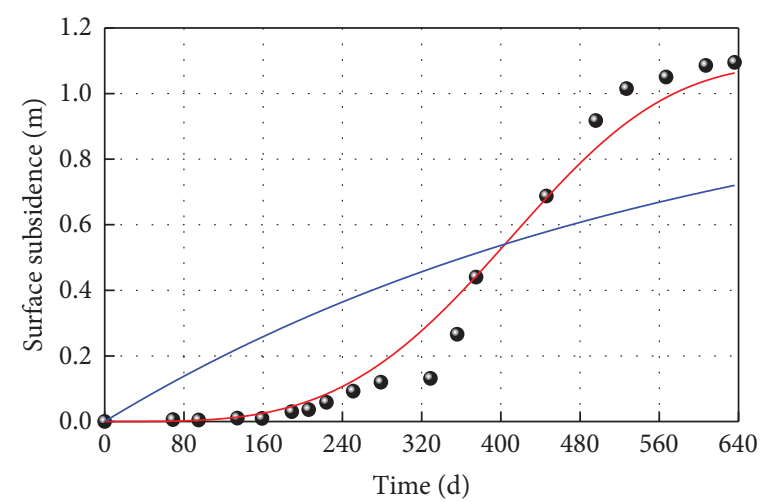

- Z45 monitoring data

Improved Knothe model curve

_ Knothe model curve

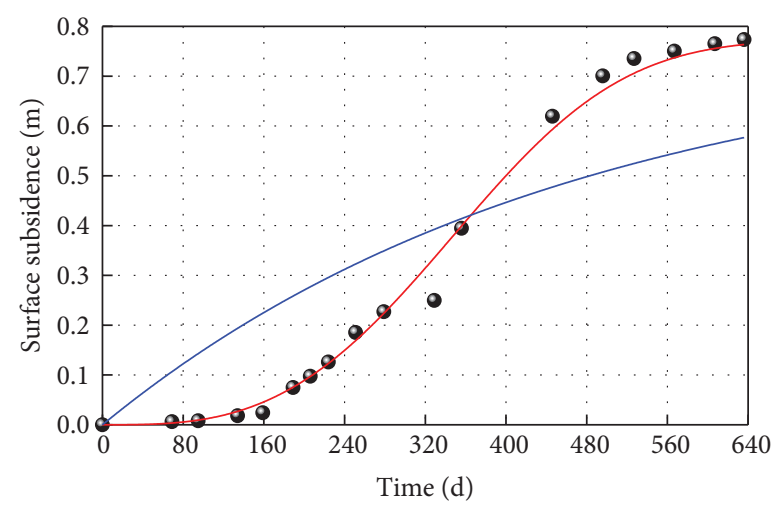

- $\quad$ Z37 monitoring data Improved Knothe model curve

_ Knothe model curve

(b)

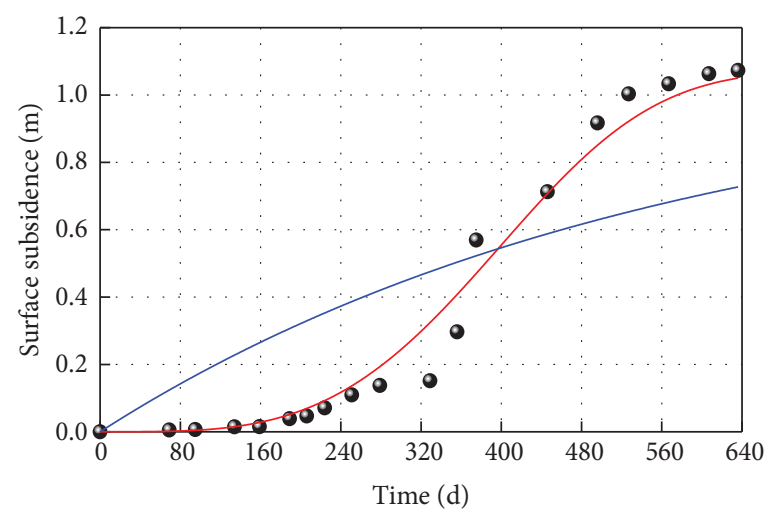

- Z44 monitoring data

Improved Knothe model curve

_ Knothe model curve

(d)

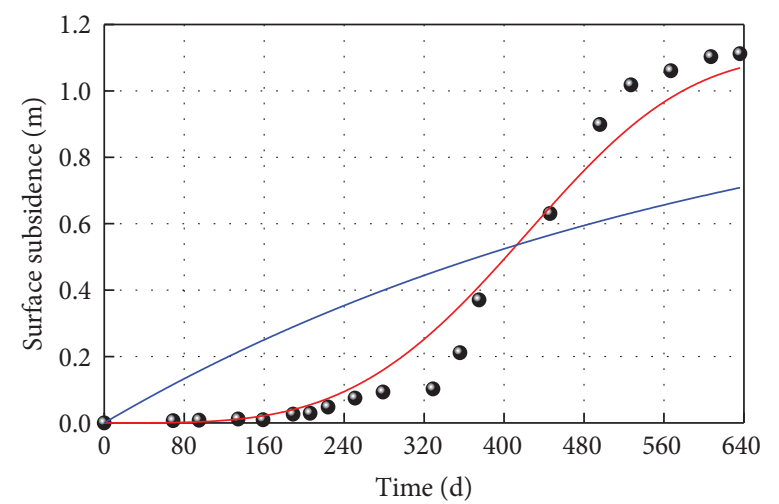

- Z47 monitoring data

Improved Knothe model curve

_ Knothe model curve

(e)

FIgUre 6: Continued. 


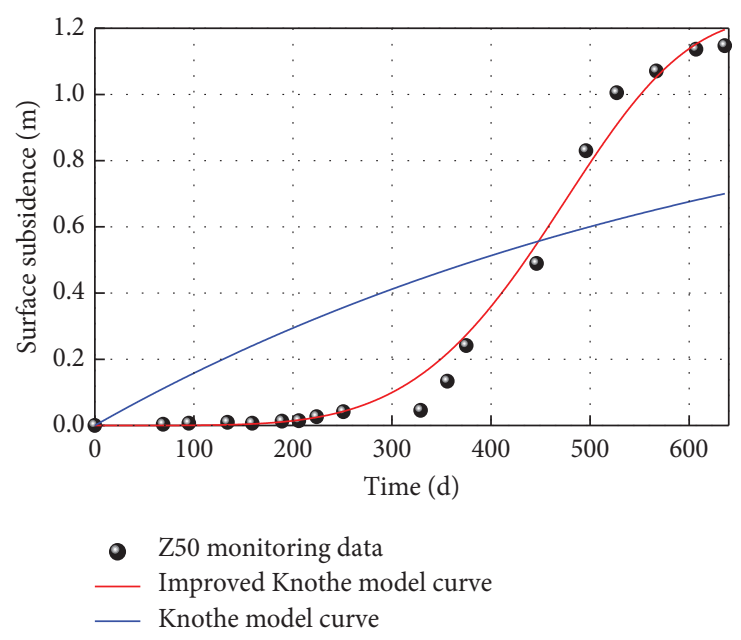

(g)

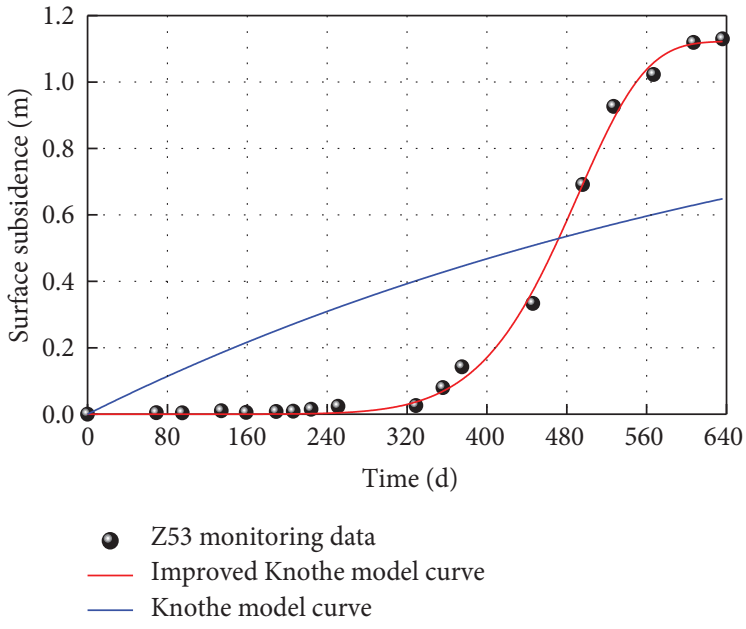

(h)

Figure 6: Comparison of two time function models. (a) Z29; (b) Z37; (c) Z41; (d) Z44; (e) Z45; (f) Z47; (g) Z50; and (h) Z53.

TABLE 2: Time influence parameters of different monitoring points.

\begin{tabular}{|c|c|c|c|c|c|}
\hline \multirow{2}{*}{ Monitoring points } & \multicolumn{3}{|c|}{ Improved Knothe model } & \multicolumn{2}{|c|}{ Knothe model } \\
\hline & $C /\left(d^{-\mathrm{n}}\right)$ & $n$ & $R^{2}$ & $c /\left(10^{-3} \cdot \mathrm{d}^{-1}\right)$ & $R^{2}$ \\
\hline Z29 & $2.24 \times 10^{-7}$ & 2.59 & 0.992 & 2.45 & 0.787 \\
\hline Z37 & $9.54 \times 10^{-9}$ & 3.09 & 0.993 & 2.15 & 0.715 \\
\hline $\mathrm{Z} 41$ & $3.30 \times 10^{-10}$ & 3.63 & 0.984 & 1.97 & 0.663 \\
\hline Z44 & $3.17 \times 10^{-10}$ & 3.60 & 0.979 & 1.78 & 0.625 \\
\hline $\mathrm{Z} 45$ & $2.33 \times 10^{-10}$ & 3.63 & 0.979 & 1.69 & 0.607 \\
\hline $\mathrm{Z} 47$ & $1.42 \times 10^{-10}$ & 3.69 & 0.973 & 1.59 & 0.586 \\
\hline $\mathrm{Z} 50$ & $0.87 \times 10^{-10}$ & 3.75 & 0.985 & 1.48 & 0.562 \\
\hline $\mathrm{Z} 53$ & $0.89 \times 10^{-10}$ & 3.79 & 0.986 & 1.31 & 0.529 \\
\hline
\end{tabular}

TABLE 3: Error of monitored and predicted values.

\begin{tabular}{|c|c|c|c|c|}
\hline \multirow{2}{*}{ Monitoring points } & \multicolumn{2}{|c|}{ Improved model } & \multicolumn{2}{|c|}{ Knothe model } \\
\hline & $m(\mathrm{~mm})$ & $f(\%)$ & $m(\mathrm{~mm})$ & $f(\%)$ \\
\hline $\mathrm{Z} 29$ & 13 & 3.3 & 66 & 16.8 \\
\hline $\mathrm{Z} 37$ & 24 & 3.1 & 158 & 20.4 \\
\hline Z41 & 48 & 4.9 & 222 & 22.9 \\
\hline $\mathrm{Z} 44$ & 76 & 6.3 & 259 & 24.1 \\
\hline $\mathrm{Z} 45$ & 62 & 5.6 & 270 & 24.6 \\
\hline $\mathrm{Z} 47$ & 72 & 6.4 & 280 & 25.2 \\
\hline $\mathrm{Z} 50$ & 63 & 5.5 & 289 & 25.2 \\
\hline $\mathrm{Z} 53$ & 64 & 4.8 & 288 & 25.5 \\
\hline Average value & 53 & 4.9 & 229 & 23.1 \\
\hline
\end{tabular}

where $W_{j}$ and $W_{l}$ are monitoring value and theoretical value, respectively; $N$ is the total number of monitoring points.

\section{Conclusions}

(1) Theoretical analysis shows that Knothe model is not suitable for describing the process of surface dynamic subsidence. An improved Knothe time function model based on an inverse "Hohai creep model" function is established from a phenomenological perspective using analogical reasoning according to the antisymmetric relationship between the unstable creep curve and the surface dynamic subsidence curve.

(2) The improved model can describe the actual process of surface subsidence and only contains two model parameters, which is convenient for practical engineering application.

(3) The result of error analysis shows that the average relative standard deviation of the improved model was only $4.9 \%$, which is far lower than the $23.1 \%$ of the Knothe model, thus verifying that the accuracy 
and reliability of the improved Knothe model are superior to those of the Knothe model.

\section{Data Availability}

The monitoring data used to support the findings of this study are included within the article.

\section{Conflicts of Interest}

The authors declare that there are no conflicts of interest regarding the publication of this paper.

\section{Acknowledgments}

This research was supported by the National Natural Science Foundation of China (51874005).

\section{References}

[1] M. S. Alam, D. Kumar, R. S. Chatterjee, and V. Upreti, "Assessment of land surface subsidence due to underground metal mining using integrated spaceborne repeat-pass differential interferometric synthetic aperture radar (DInSAR) technique and ground based observations," Journal of the Indian Society of Remote Sensing, vol. 46, no. 10, pp. 15691580, 2018.

[2] L. Zhang, H. Cheng, Z. Yao, and X. Wang, "Application of the improved Knothe time function model in the prediction of ground mining subsidence: a case study from Heze City, Shandong Province, China," Applied Sciences, vol. 10, no. 9, Article ID 3147, 2020.

[3] R. Luo, G.-Y. Li, L. Chen, Q.-Y. Yang, C.-W. Zang, and W.-Z. Cao, "Ground subsidence induced by pillar deterioration in abandoned mine districts," Journal of Central South University, vol. 27, no. 7, pp. 2160-2172, 2020.

[4] Y. Cai, X. Li, W. Xiao, and W. Zhang, "Simulation of mininginduced ground damage using orthogonal experiments to determine key parameters of super-large coalface: a case study in Shendong coalfield in China," Applied Sciences, vol. 10, no. 7, Article ID 2258, 2020.

[5] Q. F. Hu, X. M. Cui, G. Wang et al., "Key technology of predicting dynamic surface subsidence based on Knothe time function," Journal of Software, vol. 6, no. 7, pp. 1273-1280, 2011.

[6] B. L. Wang, J. L. Xu, and D. Y. Xuan, "Time function model of dynamic surface subsidence assessment of grout- injected overburden of a coal mine," International Journal of Rock Mechanics and Mining Sciences, vol. 104, no. 1-8, 2018.

[7] A. M. Suchowerska Ianec, J. P. Carter, and J. P. Hambleton, "Geomechanics of subsidence above single and multi-seam coal mining," Journal of Rock Mechanics and Geotechnical Engineering, vol. 8, no. 3, pp. 304-313, 2016.

[8] A. Kowalski, "Surface subsidence and rate of its increaments based on measurements and theory," Archives Mining Sciences, vol. 46, pp. 391-406, 2001.

[9] Q. F. Hu, X. M. Cui, L. Kang et al., "Impact of parameter on Knothe time function and its calculation model," Journal of Mining \& Safety Engineering, vol. 31, no. 1, pp. 122-126, 2014.

[10] Q. Hu, X. Deng, R. Feng, C. Li, X. Wang, and T. Jiang, "Model for calculating the parameter of the Knothe time function based on angle of full subsidence," International Journal of Rock Mechanics and Mining Sciences, vol. 78, pp. 19-26, 2015.
[11] X. Cui, J. Wang, and Y. Liu, "Prediction of progressive surface subsidence above longwall coal mining using a time function," International Journal of Rock Mechanics and Mining Sciences, vol. 38, no. 7, pp. 1057-1063, 2001.

[12] Y. C. Liu and Y. H. Zhuang, "Model for dynamic process of ground surface subsidence due to underground mining," Rock and Soil Mechanics, vol. 30, no. 11, pp. 3406-3410, 2009.

[13] Y. C. Liu, "Dynamic surface subsidence curve model based on Weibull time function," Rock and Soil Mechanics, vol. 34, no. 8, pp. 2409-2413, 2013.

[14] D. Li, "Influence of cover rock characteristics on time influencing parameters in process of surface movement," Chinese Journal of Rock Mechanics and Engineering, vol. 23, no. 22, pp. 3780-3784, 2004.

[15] M. H. Taherynia, S. M. Fatemi Aghda, A. Ghazifard, and E. Moradi, "Prediction of subsidence over oil and gas fields with use of influence functions (case study: south pars gas field, Iran)," Iranian Journal of Science and Technology, Transactions A: Science, vol. 41, no. 2, pp. 375-381, 2017.

[16] S. Konthe, "Effect of time on formation of basin subsidence," Archives of Mining Steel Industry, vol. 1, no. 1-7, 1953.

[17] L. Li, K. Wu, and D.-W. Zhou, "AutoCAD-based prediction of 3D dynamic ground movement for underground coal mining," International Journal of Rock Mechanics and Mining Sciences, vol. 71, pp. 194-203, 2014.

[18] C. Gonzalez-Nicieza, M. I. Alvarez-Fernandez, A. MenendezDiaz, and A. E. Alvarez-Vigil, "The influence of time on subsidence in the Central Asturian coalfield," Bulletin of Engineering Geology and the Environment, vol. 66, no. 3, pp. 319-329, 2007.

[19] Z. F. Yang, J. J. Zhu, Z. W. Li et al., "Analysis of law of kinematic mining subsidence by integrating InSAR and leveling measurements," Journal of Central South University (Science and Technology), vol. 46, no. 10, pp. 3743-3751, 2020.

[20] L. Nie, H. Wang, and Y. Xu, "Application of the arctangent function model in the prediction of ground mining subsidence deformation: a case study from Fushun City, Liaoning Province, China," Bulletin of Engineering Geology and the Environment, vol. 76, no. 4, pp. 1383-1398, 2016.

[21] L. L. Zhang and X. J. Wang, "Viscoelastic-plastic damage creep model for rock," Chinese Journal of Geotechnical Engineering, vol. 42, no. 6, pp. 1085-1092, 2020.

[22] W. Y. Xu, S. Q. Yang, and W. J. Chu, "Nonlinear viscoelastoplastic rheological model (Hohai model) of rock and its engineering application," Chinese Journal of Rock Mechanics and Engineering, vol. 25, no. 3, pp. 433-447, 2006.

[23] Z. Q. Chang and J. Z. Wang, "Study on time function of surface subsidence-the improved Knothe time function," Chinese Journal of Rock Mechanics and Engineering, vol. 22, pp. 1496-1499, 2003.

[24] X. J. Zhu, G. L. Guo, J. F. Zha et al., "Surface dynamic subsidence prediction model of solid backfill mining," Environmental Earth Sciences, vol. 75, no. 12, Article ID 1007, 2016.

[25] J. Z. Wang, Z. Q. Chang, and Y. Chen, "Study on mining degree and patterns of ground subsidence in condition of mining under thick unconsolidated layers," Journal of China Coal Society, vol. 28, no. 3, pp. 230-234, 2003.

[26] H. Li, J. Zha, and G. Guo, "A new dynamic prediction method for surface subsidence based on numerical model parameter sensitivity," Journal of Cleaner Production, vol. 233, pp. 1418-1424, 2019. 